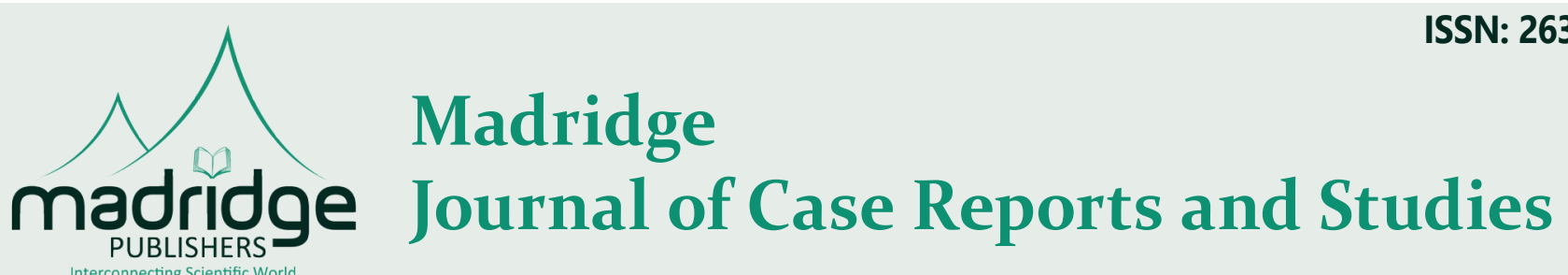

Clinical Image Article

Open Access

\title{
Bilateral Nevus of Ota: An Unusual Presentation
}

\author{
Safae Zinoune*, Zakia Douhi, Hanane Baybay, Sara Elloudi and Fatima-Zahra Mernissi \\ Department of Dermatology, Hassan II University Hospital, Fez, Morocco
}

\section{Article Info}

\section{*Corresponding author:}

\section{Safae Zinoune}

Doctor

Department of Dermatology

Hassan II University Hospital

Fès, Morocco

E-mail:dr.zinounesafae@gmail.com

Received: April 5, 2019

Accepted: April 15, 2019

Published: April 23, 2019

Citation: Zinoune S, Douhi Z, Baybay H, Elloudi S, Mernissi FZ. Bilateral Nevus of Ota: An Unusual Presentation. Madridge J Case Rep Stud. 2019; 3(2): 143-145. doi: $10.18689 /$ mjcrs-1000137

Copyright: $(2019$ The Author(s). This work is licensed under a Creative Commons Attribution 4.0 International License, which permits unrestricted use, distribution, and reproduction in any medium, provided the original work is properly cited.

Published by Madridge Publishers

\section{Clinical Findings}

A 26-year-old female presented with asymptomatic skin hyperpigmentation over the right side of the face since childhood. Clinical examination revealed a bluish to brown hyperpigmented patch involving the forehead, periorbital area, temple, cheek, and inferior sclera of the right eye (Figures 1 and 2). On examination of the left side of the face, grey-brown macules were noted on the alae root and dorsum of the nose and similarly on the inner half of the forehead, the malar region, and periorbital area. The sclera of the left eye also revealed the presence of a few bluish spots (Figures 3 and 4). Hence, a diagnosis of bilateral nevus of Ota was formulated. Dermoscopy revealed a bluish to slate grey homogenous pigmentation (Figure 5).

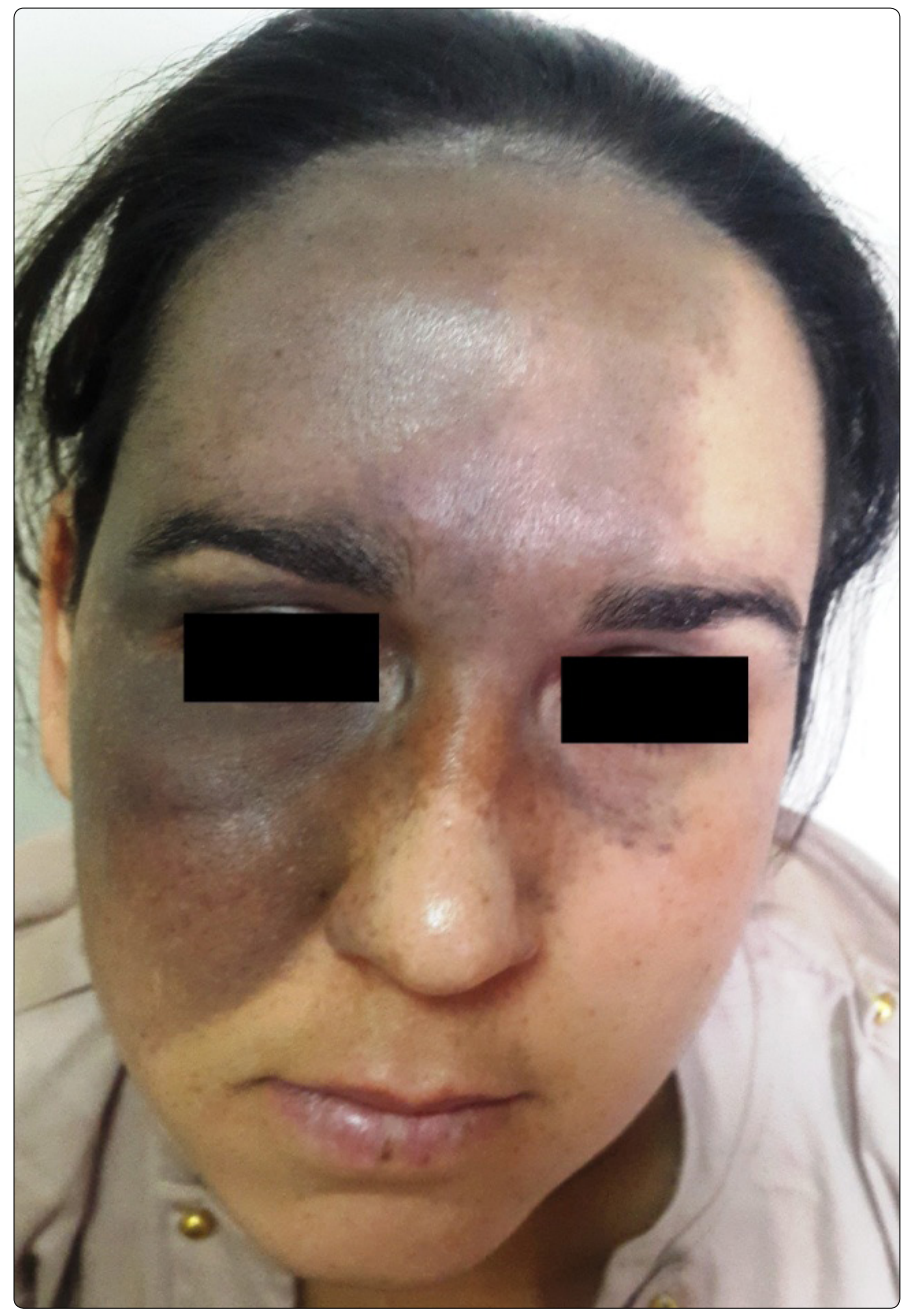

Figure 1. Bluish to brown hyperpigmentation on the right side of the face with an extension to the contralateral side. 


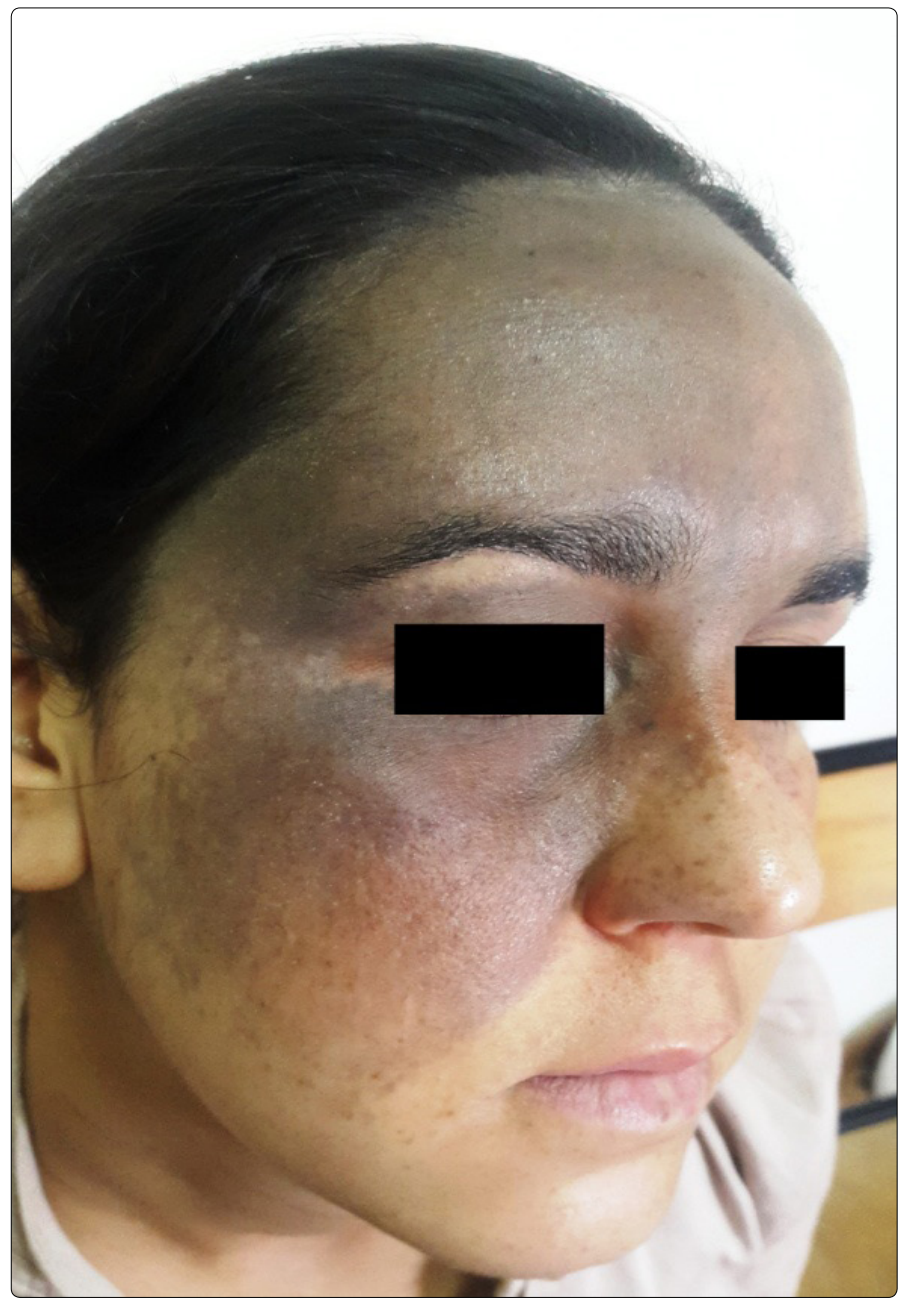

Figure 2. Bluish to brown hyperpigmentation on the right side of the face with an extension to the contralateral side.

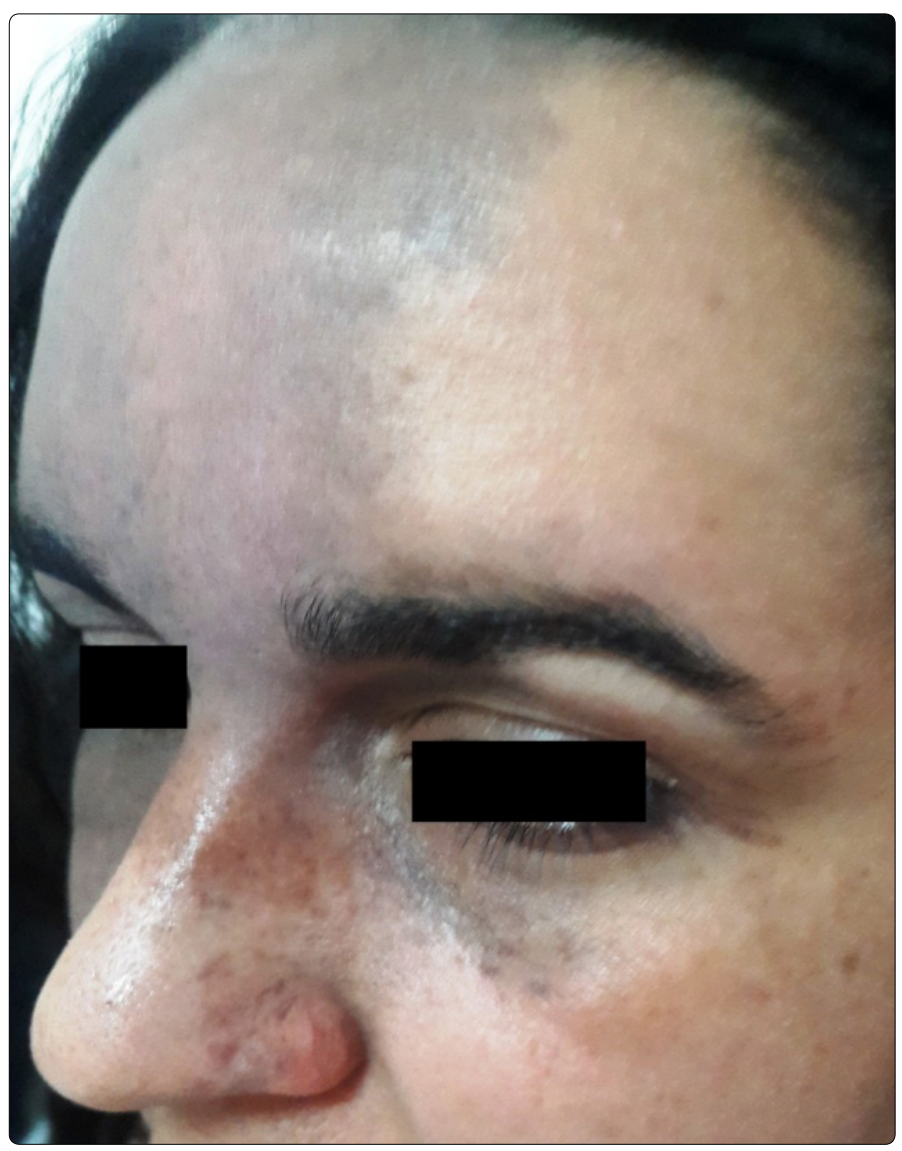

Figure 3. A blue brown macules on left nose, left malar region.

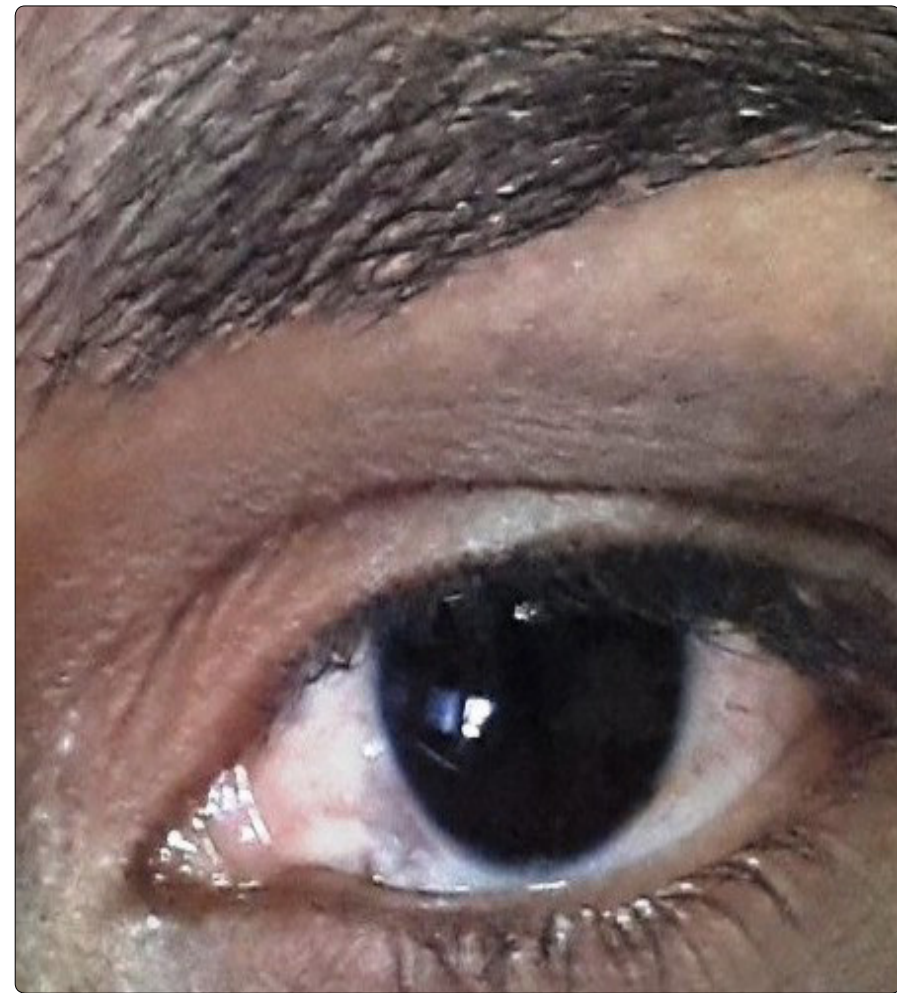

Figure 4. A blue brown macules on left peri-orbital area and few bluish discolored spots on the sclera of the left eye.

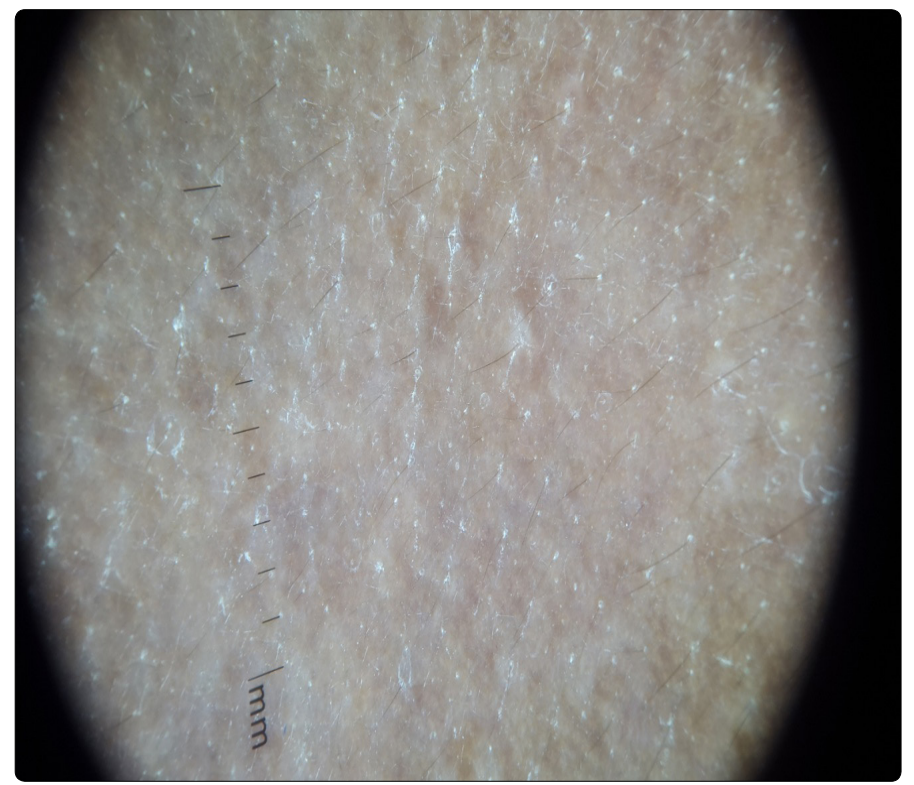

Figure 5. Bluish to slate grey homogenous pigmentation.

\section{Discussion}

Nevus of Ota, also known as nevus fusco-caeruleus ophthalmo-maxillaris, is a congenital benign dermal melanocytic nevus [1]. First described by Ota and Tanino in Japan in 1939 [1], it's more likely to be seen in persons of Asian ancestry and is typically a sporadic rather than a hereditary disorder [2]. However, bilateral involvement is rare, and it affects only approximately $1.4 \%$ of cases [3]. Tanino classified the nevus of Ota into 4 types. The bilateral type is the fourth and most severe type [3]. Clinically nevus of Ota presents as blue-gray hyperpigmented macules and patches scattered along the first and second divisions of the trigeminal nerve. Additionally, this type of dermal nevus may also affect 
the eye, oral and nasal mucosa, tympanic membrane, external auditory canal, and leptomeninges $[1,4]$. It can be associated with an open-angle glaucoma and malignant melanoma. Regarding therapy, treatment with Q-switched ruby, alexandrite, and Neodymium-doped Yttrium Aluminum Garnet laser have been successful [4].

Bilateral cases of nevus of Ota are uncommon. The sparse involvement of the contralateral side of the face made our case further unusual.

\section{References}

1. Ota M. Nevus fusco-caeruleus ophthalmic-maxillaris. The Japanese Journal of Dermatology. 1939; 46: 369.

2. Goyal S, Uwaydat SH, Phillips PH, Schaefer GB. Bilateral familial nevus of Ota. J AAPOS. 2014; 18(6): 609-610. doi: 10.1016/j.jaapos.2014.07.169

3. Yang J, Luo G, Tuyana S, Tong X, Tu Y, Tao J. Analysis of 28 Chinese Cases of Bilateral Nevus of Ota and Therapeutic Results With the Q-Switched Alexandrite Laser. Dermatol Surg. 2016; 42(2): 242-248. doi: 10.1097/ dss.0000000000000607

4. Adil M, Amin SS, Raj D, Alam M. Bilateral nevus of ota with involvement of palate: A rare case report. Indian J Paediatr Dermatol. 2018; 19: 290-292. doi: 10.4103/ijpd.IJPD_97_17 